\title{
Constituents of Acacia nilotica (L.) Delile with Novel Kinase Inhibi- tory Activity
}

\section{(c) (i)}

\author{
Authors \\ Augustine A. Ahmadu ${ }^{1}{ }^{*}$, Abdulkarim Agunu2 ${ }^{2}$, Thi-Ngoc-Dung Nguyen ${ }^{3}$, Blandine Baratte ${ }^{3}$, Béatrice Foll-Josselin ${ }^{3}$, \\ Sandrine Ruchaud ${ }^{3}$, Benoît Serive ${ }^{3 *}$, Stéphane Bach ${ }^{3}$
}

\section{Affiliations}

1 Department of Pharmaceutical and Medicinal Chemistry, Kaduna State University, Kaduna, Nigeria

2 Department of Pharmacognosy and Drug development, University of Ilorin, Ilorin, Nigeria

3 Sorbonne Universités, UPMC Univ. Paris 06, CNRS USR3151, Protein Phosphorylation and Human Disease Laboratory, KISSf Screening Facility, Station Biologique, Roscoff, France

\section{Key words}

Acacia nilotica, Leguminosae, (+)-catechin, ethyl gallate, protein kinases

received $\quad 07.07 .2017$

revised 25.09.2017

accepted 21.10.2017

\section{Bibliography \\ DOI https://doi.org/10.1055/s-0043-122397 \\ Planta Med Int Open 2017; 4: e108-e113 \\ (c) Georg Thieme Verlag KG Stuttgart · New York \\ ISSN 2509-9264}

\section{Correspondence}

Dr. Augustine Ahmadu

Department of Pharmaceutical and Medicinal Chemistry

Faculty of Pharmaceutical Sciences

Kaduna State University

Tafawa Balewa Way

\section{Kaduna}

Nigeria

Tel.: + 23/480/37033505

ahmadu2001@yahoo.com

$\circledast$ Detailed descriptions of the isolation, structural characterization, and protein kinase assays are available online at http://www. thieme-connect.de/products as Supporting Information.

\section{ABSTRACT}

Acacia nilotica (L.) Delile belongs to the genus Acacia, which includes about 1400 species in subtropical and tropical Africa including Nigeria, Senegal, Egypt, and Mozambique as well as Asia from India to Burma. This plant is traditionally used to treat several pathologies such as mouth, ear, and bone cancer. Moreover, it possesses many other biological activities (antidiarrheal, anti-inflammatory, antimicrobial, and antifungal). We report here the extraction, purification, and identification of two known compounds [ethylgallate and $(+)$-catechin] from the bark of the tree that were further tested for their inhibitory activities against a panel of disease-related protein kinases. Both compounds were active, and $(+)$-catechin showed the best activity by inhibiting nine out of fourteen protein kinases with an $\mathrm{IC}_{50}$ value in the $\mu \mathrm{g} / \mathrm{mL}$ range. This compound gave the highest activity against CLK1 with an $\mathrm{IC}_{50}$ of $2.1 \mu \mathrm{g} /$ $\mathrm{mL}$. The ethyl acetate extract and its components, such as catechins and other polyphenols, which also had protein kinase inhibitory activity, can be exploited in the research for anticancer agents.
The genus Acacia includes some 1400 species of trees and shrubs widespread throughout warm and semiarid regions of the world including Nigeria. Acacia nilotica (L.) Delile belongs to the subgenus Acacia [1, 2]. It grows naturally in tropical Africa including Nigeria, Senegal, Egypt, and Mozambique as well as Asia from India to Burma, where it was probably introduced. A. nilotica is a shrubby tree, 5-20 $\mathrm{m}$ high and is widely used in traditional medicine in Africa ( $\vee$ Fig. 1a). In the traditional Hausa ethnomedicine of Northern

\footnotetext{
* These authors share senior authorship.
}

Nigeria, the leaves and bark are used to treat diarrhea and inflammation [3]. While naringenin, and several galloyl and catechin derivatives have been isolated from the bark [4, 5], flavonol glycosides from the seeds [6], antimicrobial, antifungal, and anti-inflammatory properties have been reported previously [7-10]. Studies regarding the Fabaceae family (i.e., those of $A$. nilotica) have shown that 106 of their phytochemicals possess activities related to cancer treatment. Amongst them, A. nilotica compounds were described for anticancer activity and for cancer preventive activity [11]. 


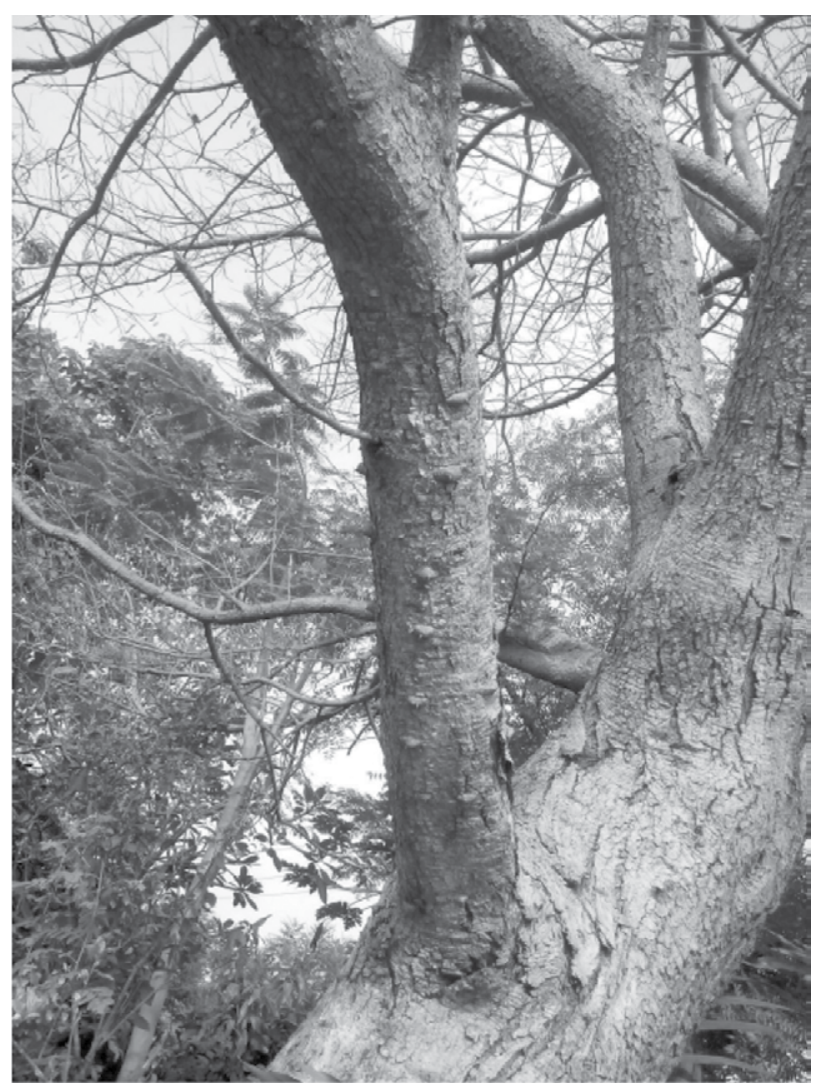<smiles>CCOC(=O)c1cc(O)c(O)c(O)c1</smiles>

(1)<smiles>Oc1cc(O)c2c(c1)O[C@H](c1ccc(O)c(O)c1)[C@H](O)C2</smiles>

(2)

- Fig. 1 a Pictures of A. nilotica branches (Zaria, Nigeria). b Chemical structures of the purified compounds.

Previously, we have isolated two new peltogynoids from the stem bark of this plant [12]. In the present study, as part of our continuing chemical exploration from the species A. nilotica, we report here the isolation of two phenolic compounds. For the first time, ethyl gallate and (+)-catechin were tested against a panel of 14 protein kinases for their potential inhibitory activity.

Bark samples of $A$. nilotica were collected in Zaria, Nigeria, in July 2015, as described previously [12]. After an ethanolic extraction, chloroform, ethyl acetate, and n-butanol fractions were produced and two major compounds from the ethyl acetate fraction were purified (compounds $\mathbf{1}$ and 2 ). Compound $\mathbf{1}$ is a pale white solid corresponding to a known compound ethyl gallate $(M W=198.17)$ according to various types of spectroscopy analyses. The chemical structure of the purified compound $\mathbf{1}$ is depicted in $\mathbf{F i g .} \mathbf{1} \mathbf{b}$.

Compound $\mathbf{2}$ is a pale yellow powder. It was validated and confirmed as the known compound (+)-catechin (MW = 290.26) according to the spectroscopy analysis. The chemical structure of the purified compound $\mathbf{2}$ is depicted in $\mathbf{F i g} \mathbf{1} \mathbf{1 b}$.

UV, NMR, and MS of these compounds were consistent with that reported in the literature for ethyl gallate $[13,14]$ and $(+)$-catechin $[15,16]$.

A primary screening of the extracts and isolated compounds against 14 disease-related protein kinases was undertaken. • Table 1 and $\triangleright$ Fig. 2a show the results of the primary screening of the extracts and compounds against a panel of 14 protein kinases. The 


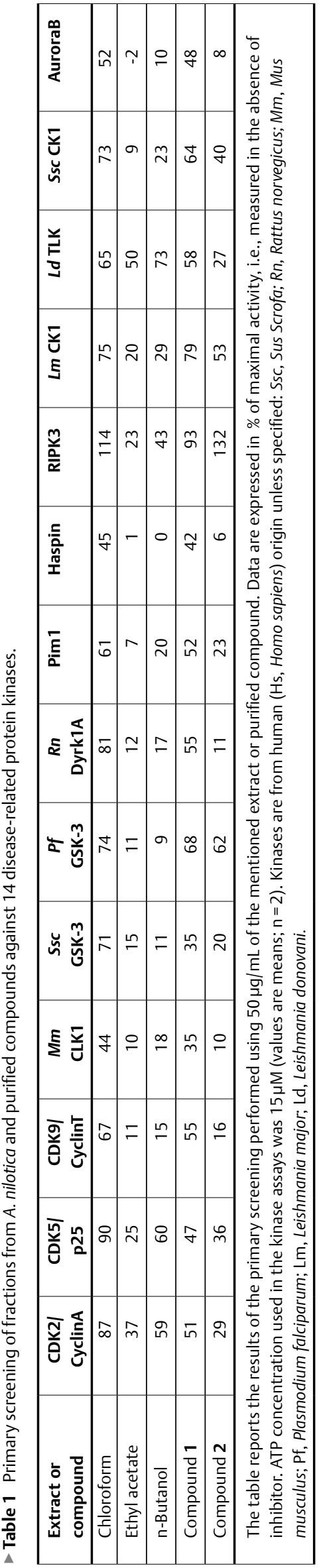

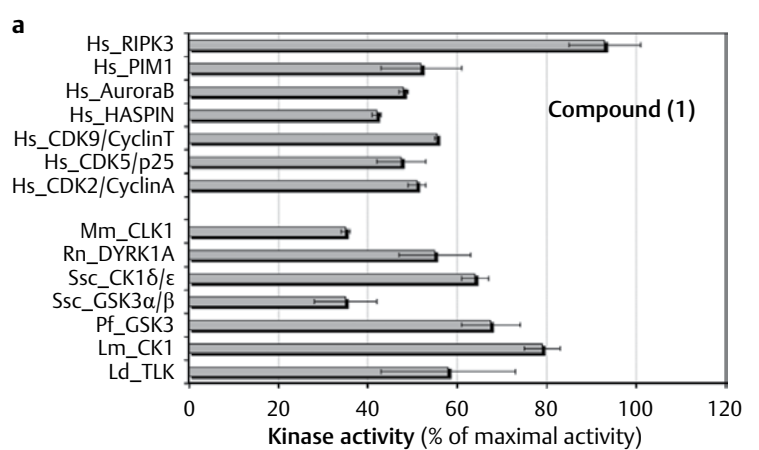

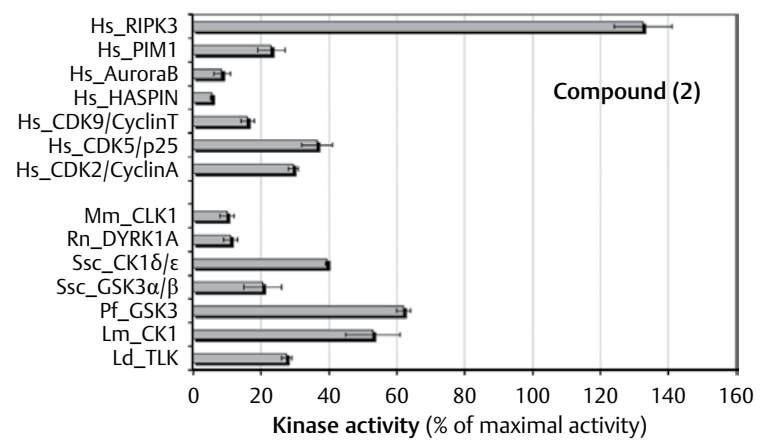

b

Mm CLK1

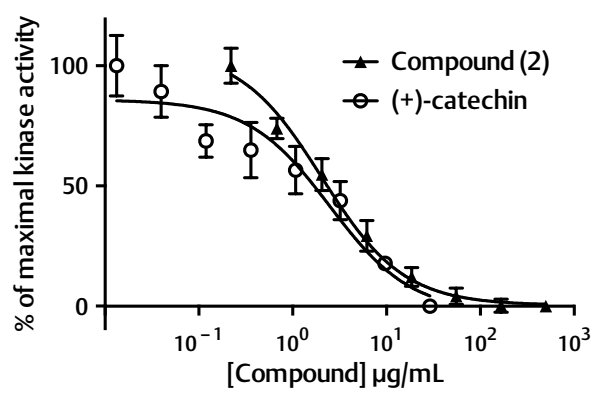

- Fig. 2 Effect of purified compounds $\mathbf{1}$ and $\mathbf{2}$ on the catalytic activity of a selected set of mammalian and parasitic kinases. a Kinase activities in the presence of $50 \mu \mathrm{g} / \mathrm{mL}$ of tested compound are expressed in \% of maximal activity, i.e., measured in the absence of inhibitor. ATP concentration used in the kinase assays was $15 \mu \mathrm{M}$ (mean \pm range; $\mathrm{n}=2$ ). Hs, Homo sapiens; Ssc, Sus scrofa; Rn, Rattus norvegicus; Mm, Mus musculus; Pf, Plasmodium falciparum; Lm, Leishmania major; Ld, Leishmania donovani. b Dose-dependent effect of compound 2 and commercial (+)-catechin on mouse CLK1. Recombinant GST-CLK1 was assayed in the presence of increasing concentrations of the two batches of $(+)$-catechin. Kinase activities are expressed in \% of maximal activity, i.e., measured in the absence of inhibitor (mean $\pm S D ; n=3$ ).

result indicates the activity that remains in the tube after treating the mentioned kinases with $50 \mu \mathrm{g} / \mathrm{mL}$ of the extracts and compounds compared to the control assay treated with DMSO. The results revealed that the chloroform extract showed the worst inhibition against the tested kinases (e.g., $50 \mu \mathrm{g} / \mathrm{mL}$ of the chloroform extract inhibits only $10 \%$ of the total CDK5 kinase activity). In contrast, the ethylacetate extract is highly active against the Haspin kinase: $50 \mu \mathrm{g} / \mathrm{mL}$ of the extract inhibits $99 \%$ of the maximal kinase activity. A similar trend was observed for the n-butanol soluble frac- 
tion and compounds 1 and 2 . The ethyl acetate and n-butanol fractions and the isolated compounds $\mathbf{1}$ and $\mathbf{2}$ were tested over a wide range of concentrations (from 0.016 to $50 \mu \mathrm{g} / \mathrm{mL}$ ) and the $I C_{50}$ values were determined from the dose-response curves. $>$ Table 2 reports the inhibitory activity of the fractions and isolated compounds against the mentioned kinases. The result revealed that the ethylacetate fraction is the most active against the Haspin kinase ( $\mathrm{IC}_{50}$ of $1.2 \mu \mathrm{g} / \mathrm{mL}$ ) followed by Aurora B kinase ( $\mathrm{IC}_{50}$ of $2.9 \mu \mathrm{g} / \mathrm{mL}$ ). This extract is more active than the $n$-butanol. Chloroform extract was not tested since the primary screening did not show any activity against the kinase panel at $50 \mu \mathrm{g} / \mathrm{mL}$. Inhibitory activity of the two compounds showed that (+)-catechin (2) was the most active protein kinase inhibitor as it inhibits the activity of nine out of the fourteen protein kinases. As shown here, (+)-catechin is inactive against HsCDK5/p25, PfCSK3, HsRIPK3, SscCK1, and LmCK1 $\left(\mathrm{IC}_{50}>172 \mu \mathrm{M}\right)$. Note that the $\mathrm{IC}_{50}$ value of compound $\mathbf{2}$ against $M m C L K 1$, the best target, was estimated at $2.1 \mu \mathrm{g} / \mathrm{mL}$ for the natural product purified from Acacia and $2.5 \mu \mathrm{g} / \mathrm{mL}$ for the molecule commercially available ( $\vee$ Fig. $\mathbf{2 b}$ ). The kinase panel tested in this study represents only $2 \%$ of the human kinome (total of 518 protein kinases). Since plant flavonoids have been shown to modulate the activities of some enzyme systems, e.g., those involved in cell surface signal transduction, immune function and transformation, tumor growth, and metastasis $[17,18]$, some other targets might also be affected.

Regarding ethyl gallate, although the literature reported numerous activities as an anti-inflammatory and antioxidant compound against various cancer cell lines and mycobacteria [19-22], no strong significant kinase inhibition was reported in this study. Compound 1 affected only four kinases with $\mathrm{IC}_{50}$ s under $50 \mathrm{\mu g} / \mathrm{mL}$ $(<252 \mu \mathrm{M})$.

(+)-Catechin (2) is naturally present in green tea. Green tea has been used daily since before $3000 \mathrm{BC}$ in China for its medicinal effects. These last decades, it has been demonstrated that catechins represent the molecular family, which hold the activity. Furthermore, the presence of polyphenol derivatives with reported proapoptotic activity [23] could prevent cancer [24]. Such molecules are not only present in green tea but also in many other land plants like Acacia. Their role is not fully understood but plants can acquire an ecological/survival benefit (e.g., space colonization, protection against grazing, activity against pathogens) to synthesize such compounds [25]. This phenomenon of so-called allelopathy is a source to identify new inhibitors of human therapeutic targets. As an example, it has been shown that the inhibitory effect of flavonoids in the growth of malignant cells could be a consequence of their interference with the protein kinase activities involved in the regulation of cellular proliferation and apoptosis [26]. Studies have shown that some polyphenols (e.g., catechins that are flavanols) possess suppressive effects in human cancer [27]. In diabetic rats, they may delay the loss of functional beta-cell mass and delay the progression of diabetes by preventing oxidative stress and betacell apoptosis [28]. Moreover, (+)-catechin has been known as an effective antioxidant by scavenging hydroxyl radicals, delaying the consumption of other antioxidants such as $\alpha$-tocopherol and $\beta$ carotene, and inhibiting lipid peroxidation. This molecule has a hepatoprotective effect against $\mathrm{CCl}_{4}$-induced acute liver injury as well, and has displayed anti-hyperglycemic activity in STZ-diabetic

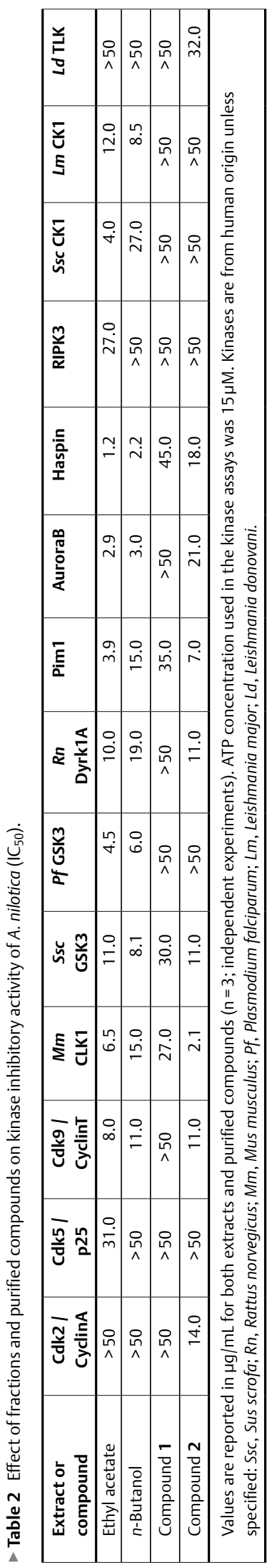


rats. Thus, (+ )-catechin might be further explored as a lead in the discovery of anticancer agents.

\section{Materials and Methods}

\section{Plant collection and extraction}

Dried pulverized bark (400 g), collected in Zaria (Nigeria), was extracted with $70 \%$ ethanol to exhaustion at room temperature. Removal of the solvent at a reduced temperature afforded a brownish crude extract $(25 \mathrm{~g})$. A portion of this extract $(20 \mathrm{~g})$ was resuspended in distilled water $(100 \mathrm{~mL})$ and partitioned successively to exhaustion with $2 \times 500 \mathrm{~mL}$ each of chloroform, ethyl acetate, and $\mathrm{n}$-butanol. Removal of the organic solvents afforded $1.25 \mathrm{~g}$ of chloroform, $3.2 \mathrm{~g}$ of ethyl acetate, and $5.2 \mathrm{~g}$ of n-butanol, respectively. Commercial (+ )-catechin was obtained from Sigma-Aldrich (99\% purity, reference product \#43412).

\section{Acknowledgements}

The authors wish to acknowledge the assistance of Dr. Zulfiqar Ali of the National Center for Natural Products Research, University of Mississippi, Oxford, MS, USA, for MS of isolated compounds and Dr. Nikolas Fokialakis of the Department of Pharmacognosy and Natural Products Chemistry, University of Athens, Greece, for the LC-MS analysis. The authors also thank Cancéropôle Grand-Ouest (axis: Marine Natural Products in Cancer Treatment), GIS IBiSA (Infrastructures en Biologie Santé et Agronomie, France), and Biogenouest (Western France Life Science and Environment Core Facility Network) for supporting the KISSf screening facilty (Roscoff, France). T.-N.-D. Nguyen is supported by the government of Vietnam (recipient of a "Project 911" PhD fellowship) and the French Embassy in Vietnam (Campus France). B. Serive is supported by a Marie Curie International Outgoing Fellowship within the $7^{\text {th }}$ European Community Framework Programme (grant \#622735). The S. Bach project is supported by the ANR/Investissements d'Avenir program via the OCEANOMICs project (grant \#ANR -11-BTBR-0008) and INCa (NECROTRAIL Program).

\section{Conflict of Interest}

The authors declare no conflict of interest.

\section{References}

[1] Pedley L. Derivation and dispersal of Acacia (Leguminosae), with particular reference to Australia, and the recognition of Senegalia and Racosperma. Bot J Linn Soc 1986; 92: 219-254

[2] Seigler DS. Phytochemistry of Acacia-sensu lato. Biochem Syst Ecol 2003; 31: 845-873

[3] Agunu A, Yusuf S, Andrew GO, Zezi AU. Abdurahman EM.Evaluation of five medicinal plants used in diarrhoea treatment in Nigeria. J Ethnopharmacol 2005; 101: 27-30

[4] Khalid SA, Yagi SM, Khristova P, Duddeck H. (+)-Catechin-5-galloyl ester as a novel natural polyphenol from the bark of Acacia nilotica of Sudanese origin1. Planta Med 1989; 55: 556-558
[5] Malan E. Derivatives of (+)-catechin-5-gallate from the bark of Acacia nilotica. Phytochemistry 1991; 30: 2737-2739

[6] Chauhan D, Singh J, Siddiqui IR. Isolation of flavonol glycoside from the seeds of Acacia nilotica. Indian J Chem 2000; 39: 719-722

[7] Abd El Nabi OM, Reisinger EC, Reinthaler FF, Still F, Eibel U, Krejs G]. Antimicrobial activity of Acacia nilotica (L.) Willd. ex Del. var. nilotica (Mimosaceae). J Ethnopharmacol 1992; 37: 77-79

[8] Mustafa NK, Tanira MOM, Dar FK, Nsanze H. Antimicrobial activity of Acacia nilotica subspp. nilotica fruit extracts. Pharm Pharmacol Commun 1999; 5: 583-586

[9] Bhargava A, Srivastava A, Kumbhare V. Antifungal activity of polyphenolic complex of Acacia nilotica bark. Indian For 1998; 124: 292-298

[10] Chaubal R, Mujumdar AM, Puranik VG, Deshpande VH, Deshpande NR. Isolation and X-ray study of an anti-inflammatory active androstene steroid from Acacia nilotica. Planta Med 2003; 69: 287-288

[11] Velusamy B, Kaliyaperumal S, Raju A. Collection and data-mining of bioactive compounds with cancer treatment properties in the plants of fabaceae family. Int J Pharm Sci Res 2016; 7: 2065-2073

[12] Ahmadu A, Abdulkarim A, Grougnet R, Myrianthopoulos V, Tillequin F, Magiatis P, Skaltsounis AL. Two new peltogynoids from Acacia nilotica Delile with kinase inhibitory activity. Planta Med 2010; 76: 458-460

[13] Backheet EY. Gallotannin and flavonoid glycosides from the stem bark of Acer negundo (L.). Bull Pharm Sci Assiut Univ 2003; 26: 77-82

[14] Leela V, Saraswarhy A. Isolation and characterization of phytoconstituents from Acacia leucophloea flowers (Roxb) Willd. Int Res J Pharm 2013; 4: 107-109

[15] de Souza LM, Cipriani TR, lacomini M, Gorin PA], Sassaki GL. HPLC ESI-MS and NMR analysis of flavonoids and tannins in bioactive extract from leaves of Maytenus ilicifolia. J Pharm Biomed Anal 2008; 47: $59-67$

[16] Zhang HM, Wang CF, Shen SM, Wang GL, Liu P, Liu ZM, Wang YY, Du SS, Liu ZL, Deng ZW. Antioxidant phenolic compounds from Pu-erh tea. Molecules 2012; 17: 14037-14045

[17] Middleton E Jr., Kandaswami C, Theoharides TC. The effects of plant flavonoids on mammalian cells: implications for inflammation, heart disease, and cancer. Pharmacol Rev 2000; 52: 673-751

[18] Huang YT, Hwang JJ, Lee PP, Ke FC, Huang JH, Huang C], Kandaswami C, Middleton E Jr. Lee MT.Effects of luteolin and quercetin, inhibitors of tyrosine kinase, on cell growth and metastasis-associated properties in A431 cells overexpressing epidermal growth factor receptor. $\mathrm{Br}$ ] Pharmacol 1999; 128: 999-1010

[19] Cui H, Yuan J, Du X, Wang M, Yue L, Liu J. Ethyl gallate suppresses proliferation and invasion in human breast cancer cells via Akt-NF-KB signaling. Oncol Rep 2014; 33: 1284-1290

[20] Mehla K, Balwani S, Agrawal A, Ghosh B. Ethyl gallate attenuates acute lung injury through Nrf2 signaling. Biochimie 2013; 95: 2404-2414

[21] Mohan S, Thiagarajan K, Chandrasekaran R, Arul J. In vitro protection of biological macromolecules against oxidative stress and in vivo toxicity evaluation of Acacia nilotica (L.) and ethyl gallate in rats. BMC Complement Altern Med 2014; 14: 257-270

[22] Kalaivani T, Rajasekaran C, Mathew L. Free radical scavenging, cytotoxic, and hemolytic activities of an active antioxidant compound ethyl gallate from leaves of Acacia Nilotica (L.) Wild. Ex. Delile subsp. indica (Benth.) Brenan. J Food Sci 2011; 76: T144-T149

[23] Mukhtar H, Ahmad N. Tea polyphenols: Prevention of cancer and optimizing health. Am J Clin Nutr 2000; 71: 1698S-1702S

[24] Jankun J, Selman SH, Swiercz R, Skrzypczak-Jankun E. Why drinking green tea could prevent cancer. Nature 1997; 387: 561

[25] Inderjit Dakshini KMM, Foy CL. Principles and practices in plant ecology: Allelochemical interactions. CRC Press; Boca Raton: 1999: 320-321 
[26] Akiyama T, Ishida J, Nakagawa S, Ogawara $\mathrm{H}$, Watanabe S, Itoh $\mathrm{N}$, Shibuya M, Fukami Y. Genistein, a specific inhibitor of tyrosine-specific protein kinases. J Biol Chem 1987; 262: 5592-5595

[27] Chen ZP, Schell JB, Ho CT, Chen KY. Green tea epigallocatechin gallate shows a pronounced growth inhibitory effect on cancerous cells but not on their normal counterparts. Cancer Lett 1998; 129: 173-179
[28] Fernández-Millán E, Cordero-Herrera I, Ramos S, Escrivá F, Alvarez C, Goya L, Martín MA. Cocoa-rich diet attenuates beta cell mass loss and function in young Zucker diabetic fatty rats by preventing oxidative stress and beta cell apoptosis. Mol Nutr Food Res 2015; 59: 820-824 